\title{
LA EMPRESA 60 DE LAS EMPRESAS MORALES DE JUAN DE BORJA. POSIBLE ORIGEN TEXTUAL DE LA IMAGEN DEL CARACOL
}

IMPRESA 60 OF THE EMPRESAS MORALES OF JUAN DE BORJA. A POSSIBLE TEXTUAL ORIGIN OF THE IMAGE OF THE SNAIL

Alejandro Martínez Sobrino

Universidad del Pais Vasco / Euskal Herriko Unibertsitatea

ABSTRACT: The author of this essay argues that the source of the image of the snail from Juan de Borja's 60th impresa of his Empresas Morales is textual, and that it can be traced back to the Picta Poesis by Aneau Barthèlemy.

KEYWORDS: Source, Snail, Impresa, Empresas Morales, Juan de Borja, Picta Poesis, Aneau Barthèlemy.

RESUMEN: El autor defiende, en el presente artículo, que el origen de la imagen del caracol que aparece en la empresa número 60 de las Empresas Morales de Juan de Borja posee un origen escrito y que puede rastrearse hasta la Picta Poesis de Aneau Barthèlemy.

PALABRAS CLAVES: Origen, Caracol, Empresa, Empresas Morales, Juan de Borja, Picta Poesis, Aneau Barthèlemy. 


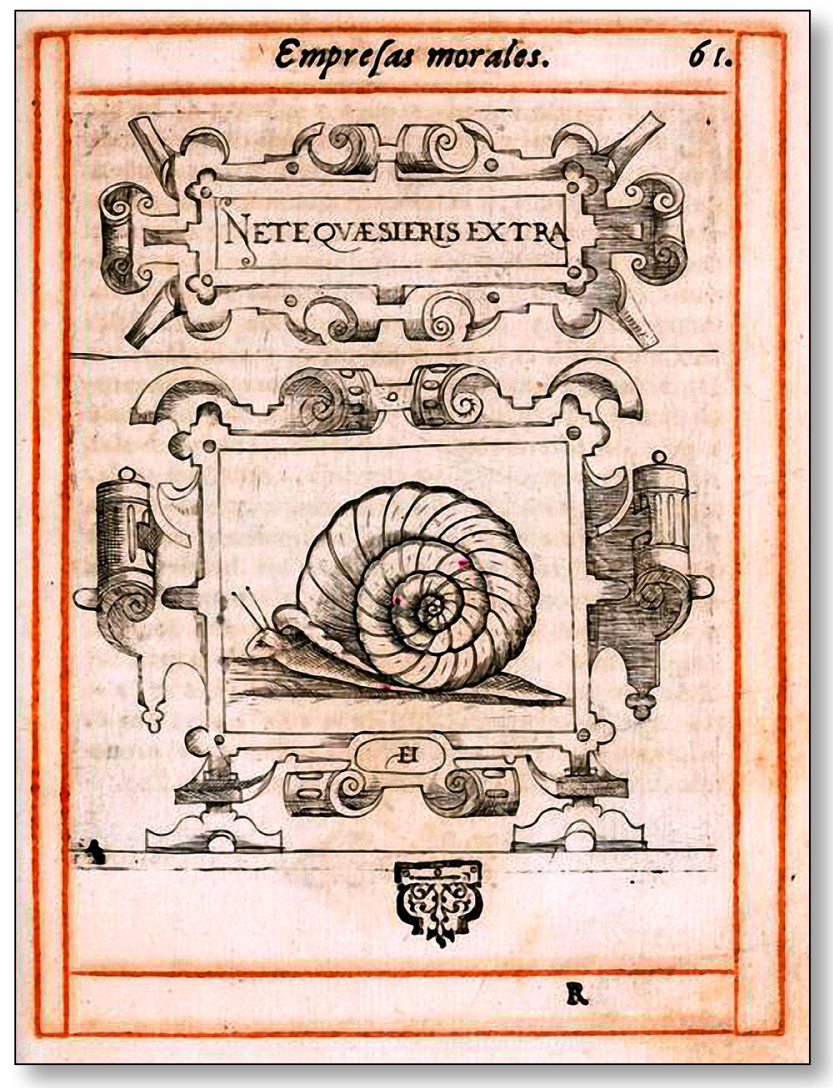

Fig. 1. Empresa LX, Borja, J. [1680]. Empresas Morales.

En otra ocasión (Martínez Sobrino, 2007), hablando de las relaciones de las Sátiras de Persio en las Empresas morales de Juan de Borja, decíamos acerca del emblema 60 que, así como el mote "Ne te quaesieris extra" (Pers. 1, 7) provenía claramente del autor latino, el origen de la pintura permanecía desconocido [fig. 1].

Afirmábamos asimismo que en el caso de la imagen del caracol, ésta, a diferencia de otras (Martínez Sobrino, 2007; García Román y Martínez Sobrino, 2007), no parecía tener su origen en un texto concreto, sino en la evolución de una imagen (Martínez Sobrino, 2007: 1068-9); proceso en el cual se había producido una "descontextualización completa» desligándose del sentido y referencia originales y ajustándose a unos nuevos (González Muñoz, 2000: 173). Un hecho agudizado en este caso porque la figura, al igual que todas en la Antigüedad y en la Edad Media, tenía un valor ambiguo. ${ }^{1}$ Rasgo que aún se veía más acentuado por la simplificación excesiva de la parte gráfica característica en Borja. ${ }^{2}$

1. R. de la Flor (1995: 13), citando a santo Tomás: «Pues una cosa puede tener semejanza con muchas, y por esta razón es imposible extraer de una cosa mencionada en la Sagrada Escritura un significado no ambiguo. El león, por ejemplo, puede representar al Señor por una semejanza, y al demonio por otra».

2. En sus empresas el dibujo adquiere una gran dependencia de la parte literaria, es decir, las imágenes son tan simples que la eficacia comunicativa de los emblemas necesita apoyarse ineludiblemente en el comentario (García Mahíques, 1998: 50). 
Así partíamos nuestra investigación desde los clásicos siguiendo los pasos dados para el caso de la empresa 39 (García Román y Martínez Sobrino, 2007). Acudíamos al De Lingua Latinae de Varrón y pasando por Símaco, autores ambos que consideraban el caracol símbolo de autosuficiencia y de soledad, llegábamos a Picinelo (Picinelli, 1979: 520), que relacionaba al molusco con el verso cincuenta y dos de la sátira cuarta de Persio. En él se aconseja, mediante el lema "tecum habita», que no se preste oído a halagos ajenos y que se haga un ejercicio de introspección gracias al cual ser capaces de conocer lo superfluo en uno mismo. Acudiendo al comienzo del verso que configura el lema de dicha empresa, "noris quam sit tibi curta supellex» ${ }^{3}$, concluíamos que Borja podría estar ofreciendo una variante de dicha sentencia al cambiar "tecum habita" por "nec quaesieris extra» en la filatería. Igualmente, decíamos que, aunque no fuera él el primero en darse cuenta de la relación existente entre los pasajes señalados -los comentarios escolares a los poemas persianos apuntaban ya a ella (Amo, 2000: 122; Dolç, 1949: 189)-, la cita mostraba la influencia manifiesta del neoplatonismo, como igualmente señalan esos mismos comentarios (Martínez Sobrino, 2009: 37), pues "ne te quaesiveris extra» se correspondería con el lema délfi-

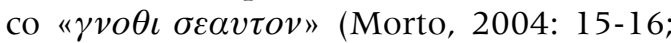
Cortés, 1988: 62), sobre cuya importancia decía el propio Borja (García Mahíques, 1998: 132): «de cuánta importancia sea al hombre su propio conocimiento, están todos los libros llenos, no sólo los sagrados, pero aún los profanos». Así, conseguíamos explicar, a través de los textos, de qué forma la imagen del gasterópodo había llegado a encarnar la idea de introspección, un uso, por otra parte, original del humanista español (García Mahíques, 1998: 152). Sin embargo, la fuente de la que habría surgido la idea de representar tal noción a través del caracol (García Mahíques, 1998: 153), y no, por ejemplo, a través de la tortuga, con la que compartía la atribución de un conjunto de significados paralelos (García Mahíques, 1998: 152), permanecía aún oculta.

Percibiendo que la respuesta que buscábamos no se encontraba en los textos clásicos, ampliamos el ámbito de búsqueda incluyendo las obras de emblemistas contemporáneos puesto que, según era preceptivo, al artista le convenía conocer y tratar a los hombres instruidos de su propio tiempo (Rensselaer, 1982: 73). Descubrimos que, poco después, Sebastián de Covarrubias había utilizado la imagen del molusco en su emblema 78 de la segunda centuria de sus

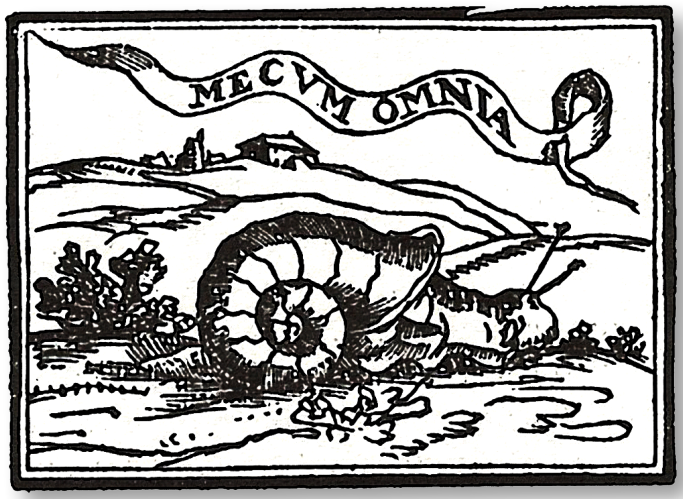

Fig. 2. El caracol, Bernat Vistarini, A., Cull, J. T. [1999]. Enciclopedia de Emblemas Españoles Ilustrados.

3. Traducción nuestra: "vive contigo: conocerás cuán corto es tu mobiliario".

4. Su hermano Juan de Horozco en el libro cuarto de sus Emblemas morales también utiliza tanto la imagen como el lema en su decimosexto emblema.

5. Si como señala Bouzy (1996: 14): «Al final de esta comitiva aparecen tres emblemistas españoles -Juan de Borja, Juan de Horozco, el mismo Covarrubias-» y posteriormente (Bouzy, 1996: 15): "Para Sebastián de Covarrubias la emblemática española es casi un asunto de familia porque, excepto una alusión a Juan de Borja en el artículo AVESTRUZ [...]», Covarrubias conocía la obra de Borja, no sería descabellado pensar que la idea de representar la pobreza con un caracol la tomara de la empresa 60, ya que en su explicación al lema Borja dice: «Porque así como el caracol nunca sale de su habitación, y en ella vive estrecha y apretadamente, de la misma manera el 
Emblemas morales para representar la pobre$\mathrm{za}^{4}$ [fig. 2]. Y al igual que en el caso de Borja, su antecedente emblemático permanecía desconocido. ${ }^{5}$

Continuamos la búsqueda entre aquellos emblemistas franceses que pudieron influir en Borja (Sebastián, 1991), y descubrimos que Aneau Barthèlemy, autor que le influenció grandemente tanto por la intención moralizadora de sus emblemas, ${ }^{6}$ como por servirle de fuente de ideas y modelo de reutilización de imágenes a las que dotar de un nuevo significado, ${ }^{7}$ en su Picta Poesis empleaba, en el emblema titulado «tecum habita», el término cochlea (caracol en latín) para referirse a una tortuga. ${ }^{8}$

Pensamos que Borja, sabedor de que cada uno de los grabados de Barthèlemy Aneau representan más de una escena, ${ }^{9}$ se inspiró en aquél para, reutilizando varios elementos tomados de él, componer dos empresas, la 41 y la 60.

Como puede verse, en el emblema francés tenemos, por un lado, la recreación de la fábula de Esopo con Júpiter rodeado de animales escuchando la respuesta de la tortuga, por otro, un poema, según es costumbre en los libros de emblemas galos (Saunders, 1986), en el que se narra la escena [fig. 3]:

\footnotetext{
Dapsilis ad mensas animalia cuncta vocarat

E terra, atque mari Iuppiter eximias.

Cuncta simul venere. Epulo testudo secundo

Venit eamque morae Iuppiter increpuit.
}

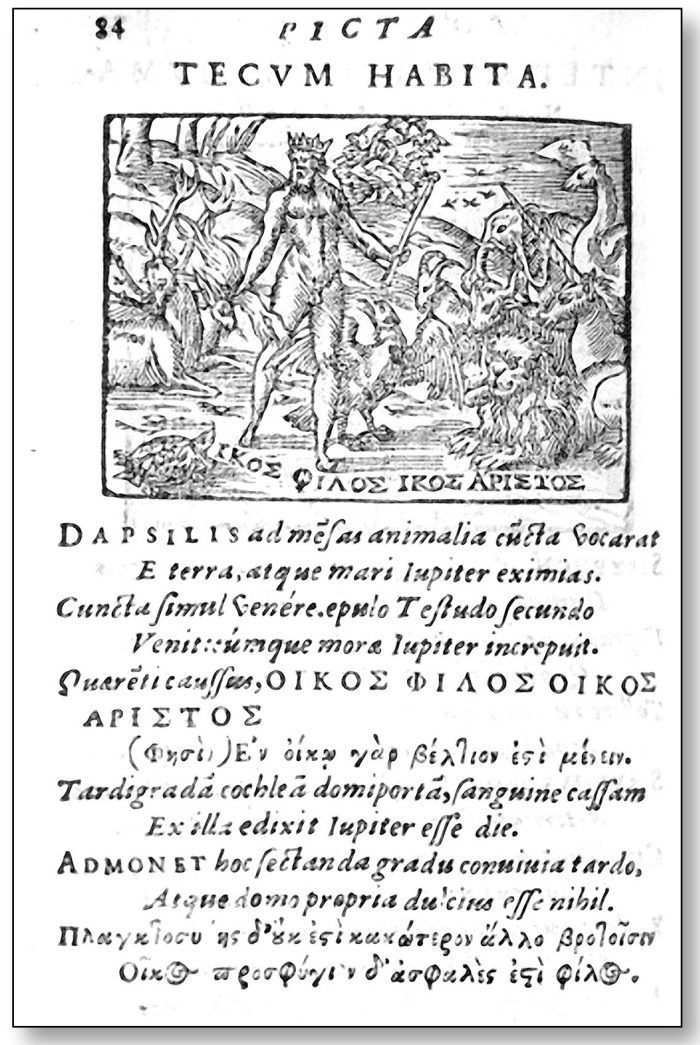

Fig. 3. Tecum Habita, Barthèlemy, A. [1552]. Picta Poesis.

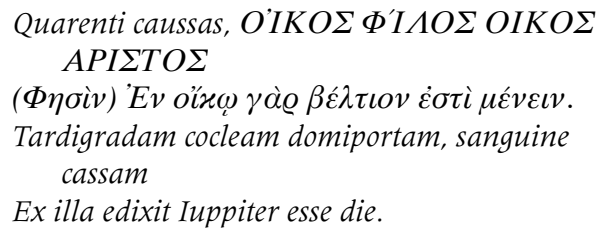

hombre que viviere consigo y no se derramare por los sentidos, alcanzará a conocer la pobreza de las alhajas que tiene de sus puertas adentro" (García Mahíques, 1998: 132).

6. «[...] the titles are of the moralizing kind, and the pattern observed is the standard one whereby the figure depicts the scene or allegorical representation which serves as the basis for the moral lesson laid down already in the title" (Saunders, 1986: 646).

7. «It is interesting to see how Aneau interprets these figures afresh, rejecting the original Ovid episodes to which they refer, and instead -like Corrozet in the Emblemes- giving a new, wholly imaginative interpretation of what he sees" (Saunders, 1986: 645).

8. Sebastián López (1991: 449), también apunta a esta posibilidad: «Aún resta otro autor francés que Borja pudo conocer, tal fue Barthèlemy Aneau, [...]. Borja en su empresa XLI [sic]: 'Domus optima' [...] presenta en el grabado a la tortuga, mientras que el autor francés muestra a Júpiter en sus bodas cuando invitó a todos los animales, [...]». 9. «It is, however, in Aenau's Imagination poetique of the following year that the complex woodcut really comes into its own, with figures in certain emblems depicting simultaneously not just two, but several scenes» (Saunders, 1986: 645).

10. Traducción nuestra: «Júpiter había convocado a todos los animales de tierra y mar a sus ricas y eximias mesas. Todos llegaron juntos. / La tortuga llegó al segundo plato y Júpiter le reconvino por su demora. A la que se le pedía 
Admonet hoc sectanda gradu convivia tardo, Atque domo propia dulcius esse nihil.

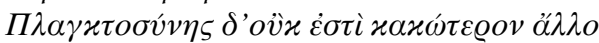

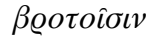

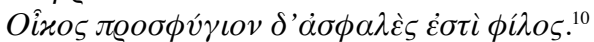

Borja toma de Aneau la idea de utilizar, para su empresa 41, el mismo protagonista de lento caminar portador de su morada, esto es, la tortuga, y se sirve como título del

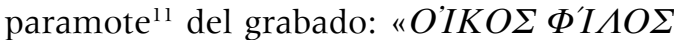
OIKO $\Sigma$ API $\Sigma T O \Sigma$ », en latín «domus optima». Paramote que aparece repetido en el hexámetro de la tercera estrofa del poema que se completa con el verso que transmite el concepto de la empresa borjiana: «'Ev

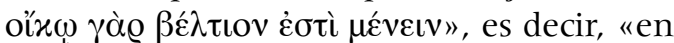
efecto lo mejor es permanecer en casa», en palabras de Borja (García Mahíques, 1998: 124): «DOMus optima, Que quiere decir, No

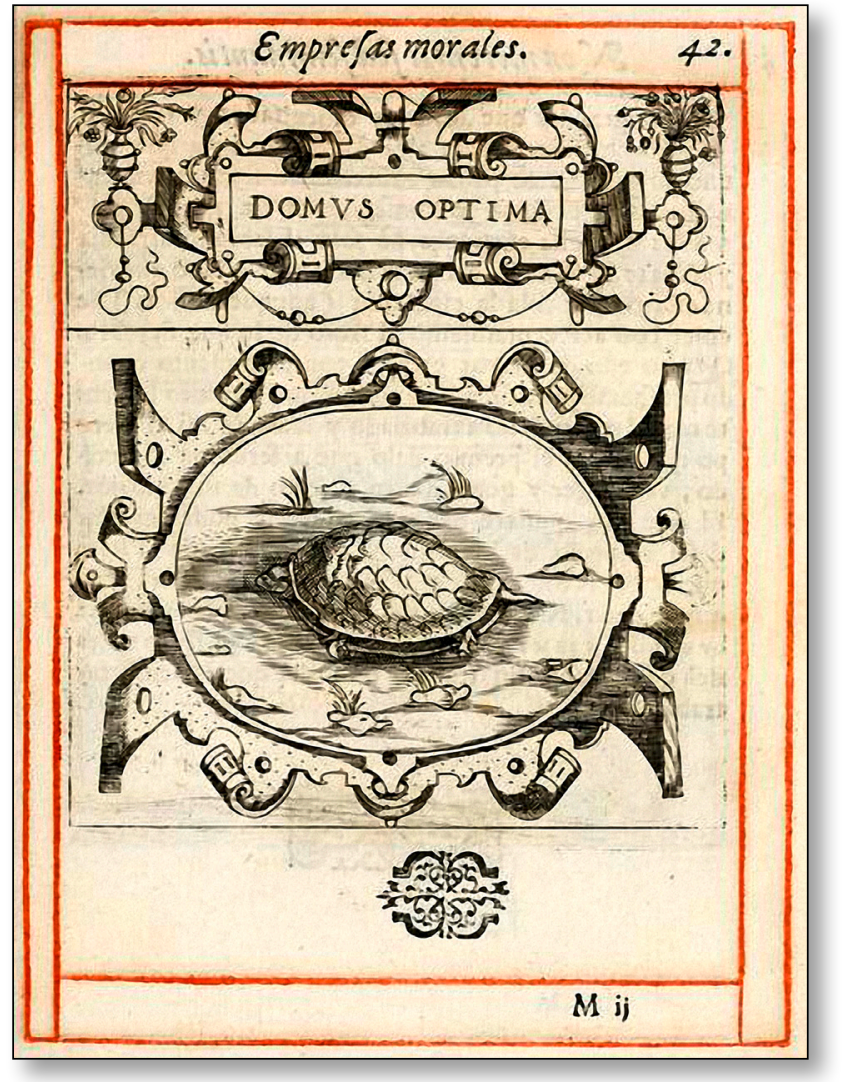

Fig. 4. Empresa XLI, Borja, J. [1680]. Empresas Morales.

explicaciones dijo: 'mi casa es mi amiga, mi casa, lo mejor. Pues lo mejor es permanecer en casa'. / Júpiter anunció que desde ese mismo día su cobertizo familiar iba a ser una concha de paso lento que lleva su casa. / Se aconseja aquí que se frecuente los banquetes con un paso lento y que no hay nada más dulce que la propia casa. / No hay nada peor para los mortales que andar errante, el hogar es un lugar seguro para quien busca refugio".

11. Sigo la clasificación establecida por García Román (2001).

12. «[...] nuestro emblemista, llevado por su afán didáctico y moral, o porque considera que la procedencia de la imagen es de sobra conocida por sus principales destinatarios, no se tomara la molestia de señalarla en la mayor 
hay cosa mejor, que la propia casa». Con lo que el autor español estaría recreando, no tanto el relato griego, como un aforismo que resulte de memorización más sencilla; aunque por ello en ocasiones se torne oscuro $^{12}$ [fig. 4].

Si continuamos con la lectura del poema, veremos que el hexámetro del cuarto dístico dice "tardigradam cochleam domiportam» para describir a la tortuga. Barthèlemy fusiona en este verso por un lado el «testudo tardigrada onerata" con el que Jerónimo (S. Hyer. In Osee. 3, 12) y Sedulio (Sed., Collect misc. 8,8 y 10, 21) describen al quelonio y el ciceroniano (Cic., Divi. 2, 133) «tardigrada [...] domiporta [...] cochlea» en el que se habla del molusco. Aneau saca provecho de la identificación metonímica que se había producido durante la Edad Media entre estos animales, para sustituir testudo por cochlea por motivos métricos; ya que no podía utilizar en un mismo verso, y menos de forma sucesiva, un tercer tetrasílabo: («tardigradam testudinem domiportam») porque su capacidad versificadora quedaría en entredicho -este tipo de construcción resulta cacofónica a los oídos latinos-. Por otra parte, la configuración silábica de tēstūdo, -̌̆nis hace que resulte métricamente complicada su utilización en un verso dactílico, por lo que reemplaza testudo por cochlea. De hecho en la versión francesa, Imagination poétique, Aneau utiliza «tortuga»: "Que la Tortue à pas tardif iroit Froide, et sans sang, sa maison porteroit Avecque soy".

Borja, que se apercibe de este hecho, aprovecha de nuevo este emblema y, deshaciendo la identificación entre ambos seres, toma el término cochlea de forma denotativa. Con ello consigue: 1) dos empresas a partir de una sola, la XLI y la LX, mediante una variatio en los símbolos; y 2) gracias a ésta, puesto que el símbolo es un signo arbitrario cuya relación con el objeto se determina arbitrariamente (Eco, 1980: 57), otorgar una nueva dimensión a la imagen del gasterópodo que tradicionalmente se había considerado un animal no muy recomendable -así lo señala Picinelo (Picinelli, 1979: 520)-, convirtiéndolo en símbolo de humildad y de autosuficiencia. Por otra parte, Borja se vio un tanto forzado a elegir

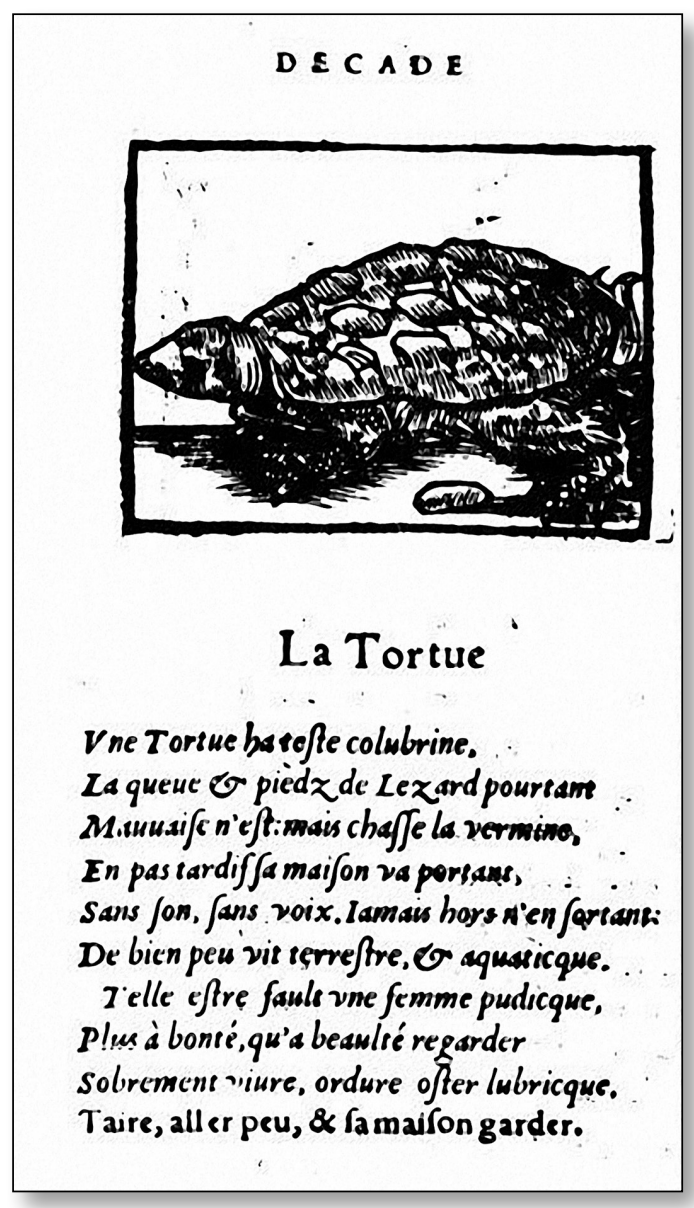

Fig. 5, La Tortue, Barthèlemy, A. [1549]. Décades de la description des animaulx.

parte de los casos, pues ello podía, además, desviar la atención del lector respecto al sentido principal del emblema. Ahora bien, si la brevedad y sencillez en la exposición facilitan la memorización y el aprendizaje del mensaje, ello no se produce en todas las ocasiones sin el riesgo de la incomprensión del lector: brevis esse laboro / obscurus fio" (García Román y Martínez Sobrino, 2007: 271).

13. La obra está dedicada a Felipe II, ver García Mahíques (1998: 11-12). 
este significado del término porque Aneau había delimitado en exceso el uso simbólico de la tortuga al volverla modelo de la mujer virtuosa en el apartado dedicado a este reptil en su obra Décades de la description des animaux, forme et vertu naturelle des animaux tant raisonnables que brutz, porque la mujer ideal calla (taire), se aleja poco (aller peu) y guarda su casa (sa maison garder) [fig. 5]. De modo que a Borja no le debió de parecer el galápago un símbolo apropiado para representar unos valores adecuados a un gobernante varón ${ }^{13}$.

La empresa 60 constituye, por tanto, un nuevo ejemplo de la artificiosa elaboración característica de Borja que, fusionando elementos aislados procedentes de fuentes diversas, se torna en maestro de la alusión. ${ }^{14}$ Así, aquí, igual que en las empresas 39 y 41, aunque las picturae, siguiendo el modelo de Alciato, ${ }^{15}$ parezcan no ayudar al esclarecimiento del mensaje por la relativa independencia que muestran con respecto al comentario; ${ }^{16}$ sin embargo, manifiestan su verdadero valor pedagógico al aludir a la verdad que el lector ha de descubrir a través de su propia experiencia, ${ }^{17}$ y encarnando, además, el autor ese ideal platónico al no limitarse a repetir a sus predecesores, sino que progresando por la vía aludida por ellos -como había hecho Barthèlemy Aneau $^{18}$ con respecto a la obra de Corrozet- aprovechando la mutabilidad de la lengua y especialmente la del significado de la imagen, se aparta de sus maestros al dibujar, en lugar de fábulas o pasajes poéticos, versos o máximas, siguiendo la estela de los Adagia erasmianos. ${ }^{19}$ Rasgo este que se vuelve característico de la emblemática hispana y que convierte a Borja en modelo a imitar. ${ }^{20}$

\section{BIBLIOGRAFÍA}

Amo Lozano, M. (ed.) [2000]. Los comentarios de Nebrija a Persio. Edición y estudio, Murcia. <http://interclassica.um.es/investigacion/tesis/otras_tesis/los_comentarios_de_nebrija_a_persio_edicion_y_ estudio/(total)/1867/(offset)/72/(ord)/ autor> 29-09-2011.

Aneau, Barthèlemy [1549]. Décades de la description des animaux, forme et vertu naturelle desanimauxtantraisonnablesquebrutz, Lyon, B. Arnoullet. <http://visualiseur.bnf.fr/ CadresFenetre?O=NUMM-70826> 2909-2011.

Aneau, Barthèlemy [1552]. Imagination poétique, Lyon, Macé Bonhomme. <http:// www.emblems.arts.gla.ac.uk/french/ books.php?id=FANb> 29-09-2011.

\footnotetext{
14. Muestra en ello la influencia de Erasmo, que defendía la independencia autorial como la multiplicación y fragmentación de las fuentes a fin de no verse atrapado en uno solo (Cave, 1979: XI).

15. "It could indeed be suggested that in certain of the emblems in the various editions of Alciati far from adding to the clarity of the emblem, the figure actually detracts from it» (Saunders, 1986: 626).

16. «Encontramos relativa independencia entre el dibujo, [...], y la declaración literaria, que sigue su propia argumentación, [...] sino que aquí el texto constituye un mecanismo de "relevo" o ampliación de los contenidos icónicos" (R. de la Flor, 1995: 61).

17. "Quien quiera enseñarnos una verdad, que no nos la diga: simplemente que aluda a ella con breve gesto, gesto que inicie en el aire una ideal trayectoria, deslizándonos por la cual lleguemos nosotros mismos a los pies de la nueva verdad" (Ortega y Gasset, 2010: 109).

18. "The collection is interesting because, like Corrozet's Emblemes, the text is composed on the basis of already existing figures, and the title Imagination poetique is an apt one, describing precisely what the book is, an exercise in ingenuity and imaginative creativity on the basis of a given picture» (Saunders, 1986: 645).

19. "DOMUS AMICA tiene su fuente en las fábulas de Esopo y fue recogido por Erasmo en sus adagios, ofreciéndonos su versión latina [...]» (García Román, en prensa: 9).

20. "Con Juan de Borja se ha creado la Empresa hispánica, un modelo de emblemática [...]» (García Mahíques, 1996: 78).
} 
Aneau, Barthèlemy [1552]. Picta poesis, Lyon, Macé Bonhomme. <http://www. emblems.arts.gla.ac.uk/french/books. php?id=FANa $>$ 29-09-2011.

Bernat Vistarini A., y Cull, J. T. [1999]. Enciclopedia de Emblemas Españoles Ilustrados, Madrid, Akal.

BorJA, Juan de [1680]. Empresas Morales, Bruselas, Francisco Foppens. <http://rosalia.dc.fi.udc.es/emblematica/> 29-092011

Bouzy, C. [1996]. "Emblemas, empresas y hieroglíficos en el Tesoro de la lengua de Sebastián de Covarrubias», en S. LóPEz Poza (ed.), Literatura Emblemática Hispánica. I Simposio internacional La Coruña, Septiembre, 1994, La Coruña, Universidade, 13-43.

Cave, T. [1979]. The Cornucopian text. Problems of Writing in the French Renaissance, Oxford, Oxford University Press.

Cortés, R. (ed.) [1988]. Persio. Sátiras. Edición Bilingüe, Madrid, Cátedra.

Covarrubias, S. de [1610]. Emblemas Morales, Madrid, Luis Sánchez. <http://rosalia. dc.fi.udc.es/emblematica/> 29-09-2011.

Díaz de Bustamante, J. M. [1996]. "Sobre los orígenes del emblema literario: Lemmata y contexto», en S. López PozA (ed.), Literatura Emblemática Hispánica. I Simposio internacional La Coruña, Septiembre, 1994, La Coruña, Universidade, 61-73.

Dolç, M. [1949]. A. Persio Flaco Sátiras, Barcelona, CSIC.

Eco, U. [1980]. Signo, F. Serra Cantarel (trad.), Barcelona, Editorial Labor.

García Mahíques, R. [1996]. "Las Empresas morales de Juan de Borja: matizaciones en torno a Emblemática e Iconología», en S. López Poza (ed.), Literatura Emblemática Hispánica. I Simposio internacional La Coruña, Septiembre, 1994, La Coruña, Universidade, 75-93.

GARCÍA MAHÍQUes, R. [1998]. Empresas morales de Juan de Borja: Imagen y palabra para una iconología, Valencia, Ayuntamiento de Valencia.
García Román, C. [en prensa]. "Motes, pseudomotes y paramotes en la Emblemática Hispánica», comunicación presentada en el III Seminario Internacional de Emblemática Filippo Picinelli, Zamora (Michoacán, México), 1-2 de marzo de 2001.

García Román, C. y Martínez sobrino, A. [2007]. "Las fuentes Textuales de la pictura de la empresa 39 de las Empresas Morales de Juan de Borja», en J. Alonso Aldama, C. García Román, Idoia MamoLAR SANCHEZ (eds.), $\Sigma$ TI $\Sigma$ AMMOY $\mathrm{IIE} \Sigma$ TOY OMHPOY, Homenaje a la Profesora Olga Omatos, Vitoria-Gasteiz, UPV/EHU, 267-277.

GonZÁLEz Muñoz, F. [2000]. «Lema literario y 'pictura' en los 'Emblemas morales' de Sebastián de Covarrubias», en S. LÓPEZ Poza (ed.), Estudios sobre Emblemática Española. Trabajos del grupo de investigación Literatura emblemática hispánica, A Coruña, Universidade da Coruña/Sociedad de Cultura Valle Inclán (Colección Sielae), 167-175.

Horozco, J.de [1601]. Emblemas Morales, Agrigento. <http://digibug.ugr.es/handle/ 10481/13029> 29-09-2011.

Martínez Sobrino, A. [2007]. "Pervivencia de la Antigüedad Clásica en la Emblemática hispánica. El caso de las Saturae de Persio en las Empresas Morales de Juan de Borja», en R. García Mahíques y V. ZuRIAGA SENEnT (eds.), Imagen y cultura. La interpretación de las imágenes como Historia cultura. Actas del VI Congreso Internacional de la Sociedad Española de Emblemática, celebrado entre el 16 y 19 de octubre de 2007 (2 Vol.), Valencia, Biblioteca Valenciana, Vol. II., 1063-1071.

Martínez Sobrino, A. [2009]. Edición y estudio crítico de los comentarios de Jodoco Badio Ascensio a las sátiras de Persio, Vitoria-Gasteiz, UPV-EHU, (tesis inédita).

Morton Braund, S. (ed.) [2004]. Juvenal and Persius, Cambridge Massachusetts/London, Loeb Classical Library. 
Ortega y Gasset, J. [2010]. Meditaciones del Quijote, J. Marías (ed.), Madrid, Cátedra.

Picinelli, F. [1687]. Mundus Symbolicus in Emblematum Universitate Formatus, Explicatus et tan Sacris, quam profanis Eruditionibus ac Sententis illustrates, Coloniae Agrippinae, Hermanni Demen. [Ed. facssímile, «Emblematische Cabinet. Band VIII", Hildesheim-New York, Georg. Olms, 1979].

Rensselaer, W. [1982]. Ut pictura poesis. La teoría humanística de la pintura, C. LUCA DE Tena (trad.), Madrid, Cátedra.
Rodríguez De la Flor, F. [1995]. Emblemas. Lecturas de la imagen simbólica, Madrid, Alianza.

SAunders, A. [1986]. "Picta Poesis: The relationship between figure and text in the sixteenth-century French emblem book", en Bibliothèque d'Humanisme et Renaissance, XLVIII, 621-652.

Sebastián López, S. [1991]. "Influencias e interferencias en los orígenes de la emblemática española», en Actas del I Simposio Internacional de Emblemática, Teruel 1 y 2 de octubre de 1991, Teruel, Instituto de Estudios Turolenses, 445-453. 